\title{
Makine Bağlantı Elemanlarını Ayıklama Sistemi Geliştirilmesi
}

\author{
Bedirhan Tuncer $^{1 *}$, Fatih Sultan Frrıl ${ }^{1}$, Seyit Gündoğan ${ }^{1}$, Ali Kalkanlı ${ }^{1}$, Cenk Ulu ${ }^{2}$ \\ ${ }^{1}$ Yıldız Teknik Üniversitesi, Makine Fakültesi, Mekatronik Mühendisliği Bölümü, İstanbul, Türkiye \\ ${ }^{2}$ Yıldız Teknik Üniversitesi, Makine Fakültesi, Mekatronik Mühendisliği Bölümü, İstanbul, Türkiye (ORCID: 0000-0002-8588-6247)
}

(Bu yayın 26-27 Haziran 2020 tarihinde HORA-2020 kongresinde sözlü olarak sunulmuştur.)

(DOI: 10.31590 /ejosat.779981)

ATIF/REFERENCE: Tuncer, B., Fırıl, F. S., Gündoğan, S., Kalkanlı, A. \& Ulu, C. (2020). Makine Bağlantı Elemanlarını Ayıklama Sistemi Geliştirilmesi. Avrupa Bilim ve Teknoloji Dergisi, (Special Issue), 288-289.

\section{$\ddot{O} \mathbf{z}$}

Makine bağlantı elemanları (cıvata, somun, pul, vb.) üretim, bakım, onarım ve montaj işlemlerinin ayrılmaz bir parçasıdır. Daha önce kullanılmış ancak sağlam olan makine bağlantı elemanları yeni işlemlerde tekrar kullanılabilmektedir. Bu nedenle, genellikle bir alanda karışık şekilde toplanmış makine bağlantı elemanları bir ayıklama işleminden geçirilir. Böylece sağlam olan bağlantı elemanları sınıflandırılarak ayıklanır ve kullanılamayacak durumda olanlar hurdaya gönderilir. Bu ayıklama işlemi genellikle insan gücü ile yapılmaktadır. Burada ortaya çıkan insan kaynaklı hatalar ve iş gücü kaybı verimliliği düşürmektedir. Bu çalışmada, karışık halde bulunan makine bağlantı elemanlarını görüntü işleme metodu kullanılarak tür, boyut ve metrik olarak sınıflandıran bir otomasyon sisteminin geliştirilmesi anlatılmıştır. Sistem titreşimli besleyici, konveyör bant, görüntü işleme birimi ve paketleme mekanizması olmak üzere 4 ana birimden oluşmaktadır. Bağlantı elemanları, konveyöre gönderilmek üzere titreşim besleyiciye yerleştirilmektedir. Sıralanmış elemanlar konveyör ile görüntü işleme ünitesine aktarılmakta ve bu ünitede tür, boyut ve metrik olarak sınıflandırılmaktadır. Sınıflandırılmış elemanlar paketleme mekanizmasındaki ilgili kutulara yerleştirilmektedir. Bu işlemler sırasında tüm sistem verileri kayıt altına alınarak bilgisayar ortamına aktııılmakta ve geliştirilen arayüz sayesinde kullanıcının bu verilere ulaşması sağlanmaktadır. İlk olarak, sistemin elektrik ve mekanik tasarımları belirlenen tasarım kriterlerine bağlı olarak gerçekleştirilmiştir. Ardından, grafik kullanıcı arayüzü, kontrol ve görüntü işleme algoritmaları geliştirilmiştir. Mekanik parçaların üretiminden sonra sistemin entegrasyonu tamamlanmış ve fonksiyonel testler başarıyla gerçekleştirilmiştir. Test sonuçları, geliştirilen sistemin görüntü işleme tabanlı sınıflandırma başarı oranının \% 90' in üzerinde olduğunu göstermektedir.

Anahtar Kelimeler: Makine Bağlantı Elemanı, Görüntü İşleme, Ayıklama, Titreşimli Besleyici, Konveyor Bant, Kullanıcı Arayüzü.

\section{Development of a Machine Fasteners Classification System}

\begin{abstract}
Machine fasteners (bolts, nuts, washers, etc.) are an integral part of the production, maintenance, repair, and assembly processes. Machine fasteners that have been previously used but are scatheless can be reused in new processes. For this reason, used machine fasteners that are generally mixed in an area are subjected to a sorting process, and those that cannot be used are scrapped. In this process, the fasteners are sorted with respect to their types, sizes, and metrics. This sorting process is usually done with manpower and this leads to errors and loss of labor which diminish productivity. In this study, the development of an automation system that classifies mixed machine fasteners as type, size, and metric using the image processing method is presented. The system consists of four main units: a vibrating feeder, a conveyor belt, an image processing unit, and a packaging mechanism. The fasteners are put in the vibration feeder in order to be sent to the conveyor. The elements lined up are transferred with the conveyor to the image processing unit and are classified as type, size, and metric in this unit. Classified elements are placed in the relevant boxes in the packaging mechanism. During these processes, all system data are recorded and transferred to the computer environment, and the user can access these data thanks to the developed user interface. Firstly, the electrical and mechanical designs of the system are done depending on the specified design criteria. Then, graphical user interface, control, and image processing algorithms are developed. After the production of mechanical parts, the integration of the system is completed and functional tests are carried out successfully. Test results show that the success rate of the developed image processing algorithm is over $90 \%$.
\end{abstract}

Keywords: Machine Fastener, Image Processing, Sorting, Vibration Feeder, Conveyor Belt, User Interface.

* Sorumlu Yazar: Yıldız Teknik Üniversitesi, Makine Fakültesi, Mekatronik Mühendisliği Bölümü, İstanbul, Türkiye, bdrhntncr@gmail.com 


\section{Giriş}

Endüstride üretim, bakım-onarım, montaj vb. atölyelerinde cıvata, somun, pul gibi makine bağlantı elemanları oldukça fazla kullanılmaktadır. Bu elemanlar kullanım sonrası veya kullanım için koyulan alanlarda birbirlerine karışmaktadır. Bu karışma sonucu tekrar kullanılabilmeleri için ayıklanmaları ve türlerine göre sınıflandırılmaları gerekmektedir. Bu ayıklama işlemi insan gücü ile yapılmaktadır [1]. Bu durum iş gücü ve zaman kaybına, aynı zamanda da insan kaynaklı hataların artmasına neden olarak ayıklama sürecini verimsiz hale getirmektedir.

$\mathrm{Bu}$ verimsizliği ortadan kaldırmak için ayıklama işlemlerinde insan gücüne alternatif olarak makine bağlantı sınıflandırma sistemleri kullanılmaktadır. Bu sistemler genel olarak konveyör mekanizması, titreşimli besleyici, görüntü işleme ünitesi gibi alt sistemlerden oluşur. Bu sistemlerin tasarımında boyut ve ağırlık, çalışma hızı, kararlılık, alt sistemlerin yerleşimi ve bakım kolaylığı gibi tasarım kriterler göz önünde bulundurulmaktadır.

Konveyör bant sistemleri, katı malzemelerin sürekli bir şekilde uzun mesafelere yatay veya belirli sınırlar dahilinde eğimli olarak taşınması işlerinde[2] kullanılmaktadır. Konveyör sistemleri, malzeme taşıma ve depolamada dayanıklı ve güvenilirdir. Konveyör bant için kauçuk bant ve modüler bant [3]gibi malzemeler kullanılmaktadır. Konveyör hareketini sağlamak için adım motoru, doğru akım motoru ve özellikle yüksek tork gerektiren uygulamalarda redüktörlü motorlar kullanılmaktadır. Konveyör bant sistemlerinin avantajları düşük işletme ve bakım maliyeti, sürekli üretim, kolayca genişletilebilir olarak görülmektedir. Yüksek yatırım maliyeti, daha az esneklik ve taşınan malzemenin boyutunun sınırlandırılması bu mekanizma için dezavantaj kabul edilmektedir [4].

Cihazın temel amaçlarından biri olan parça tanımlama, boyut ölçümü gibi işlemlerde eddy akımı [5], görüntü işleme [6], makine öğrenmesi [7], yapay zeka [8] gibi metodlar kullanılmaktadır. Eddy akımı yöntemi hem kurulumu hem de maliyeti açısından dezavantajlar getirmektedir. Bu çalışmada bu işlemler için görüntü işleme metotları kullanılmaktadır.

Görüntü işleme aşamasında, nesnelerin tespit edilmesi veya tanınması amacıyla yapılan çalışmalarda nesnelere ait basit özellikler kullanılarak hızlı ve etkili nesne tanıma [9], karmaşık arka plan çıkarımı ile tanıma [10], şekil tanıma, renk tanıma, kenar ve köşe tanıma, istatistiksel örüntü tanıma, şablon eşleme gibi çeşitli yöntemler kullanılmaktadır [11]. Ayrıca kalite kontrol ve ayıklama işlemi gerçekleştirilen makinelerde, görüntü işleme yöntemi için yüksek çözünürlükte kamera kullanılarak görüntünün net bir şekilde alınması amaçlanmaktadır [12,13]. Benzer çalışmalarda görüntü işleme aşamasında ise Raspberry [14], NVIDIA Jetson [15] gibi işlemci kartları kullanılmaktadır.

Benzer sistemlerde bağlantı elemanlarının tanımlama, boyutlandırma gibi safhalarda çeşitli görüntü işleme yöntemlerine başvurulmaktadır [16]. Bu çalışma kapsamında geliştirilen sistemde ise görüntü işleme kullanılmasının yanı sıra, standart makine elemanları çizelgesi ile bağlantı elemanlarının boyutlarının doğrulanması sağlanarak hata oranının en aza indirgenmesi hedeflenmiş̧tir.

Bağlantı elemanlarını ayıklama işleminde parçaların sıralı bir şekilde taşınması gerek görüntü işleme gerekse cihazın çalışma doğruluğu açısından önem arz etmektedir. Titreşimli besleyiciler, eksantrik ağırlıkların titreşiminden yararlanarak katı parçaları istenilen sıraya dizmek için kullanılan cihazlardır. Benzer çalışmalarda, parçaların sıralı bir şekilde ilerlemesi için robot kol ve tutucu [17], çanak vibrasyon [18] ve lineer vibrasyon [19] gibi yöntemler kullanılmıştır. Robot kol ve tutucular, işlem hızı açısından avantajlar sağlasa da maliyet açısından dezavantajlar getirmektedir. Lineer vibrasyonlar da çanak vibrasyonlara göre daha fazla yere ihtiyaç duyduklarından bu çalışmada çanak vibrasyon tercih edilmiş̧ir.

Literatür araştırmasında incelenen sistemlerde, parçanın tanımlanması sonrasında ayırma işlemi pnömatik olarak ya da mekanik aksamlar ile yapılmaktadır [20]. Bu çalışmada ise paketleme mekanizmasında kullanılacak mekanik düzenek ile kutular kolayla sökülüp takılabilir olarak yapılmıştır. Bu sayede kullanıcıya kullanışı ıir sistem sunulmaktadır.

$\mathrm{Bu}$ çalı̧̧mada makine bağlantı elemanlarını tür, metrik, uzunluk ve standart dışı olarak sınıflandırılma işlemlerini gerçekleştirecek bir ayıklama sistemi geliştirilmesi anlatılmaktadır. Sistem titreşimli besleyici, konveyör bant, görüntü işleme birimi ve paketleme mekanizması olmak üzere dört ana birimden oluşmaktadır. Gerçekleştirilen tasarımda titreşimli besleyici ünitesi yardımı ile bağlantı elemanları sıraya sokulmaktadır. Sıralı bir şekilde gelen bağlantı elemanları, konveyör mekanizması ile görüntü işleme alanına taşınmaktadır. Bu alanda görüntü işleme yöntemi ile elemanların tür, metrik ve uzunluk olarak bilgileri tanımlanmaktadır. En son aşama olarak tanımlama işlemi tamamlanan elemanların arayüzden girilen bilgiler dikkate alınarak uygun kutulara yerleştirme işlemi gerçekleştirilmektedir. Çalışma boyunca tüm sistem verileri, eleman tanımlama ve paketleme verileri kayıt altına alınmaktadır. Sistem tasarımında ilk olarak tasarım isterleri belirlenmiş ve bu isterlere bağlı olarak sistemin elektrik ve mekanik tasarımları gerçekleştirilmiştir. Bu tasarımların tamamlanmasının ardından grafik kullanıcı arayüzü, kontrol ve görüntü işleme algoritmaları geliştirilmiştir. Sistemin tasarlanan mekanik parçaları ürettirilmiş ve sistem entegrasyonu gerçekleştirilmiş̧tir. Sistem entegrasyonundan sonra sistemin fonksiyonel testleri başarıyla gerçekleştirilmiş ve test sonuçları ile geliştirilen sistemin görüntü işleme tabanlı sınıflandırma başarı oranının \% 90' ın üzerinde olduğunu gösterilmiştir.

\section{Sistem Tasarımı}

\subsection{Tasarım İsterleri}

Paydaşlarla yapılan görüşmeler ve gerçekleştirilen piyasa araştırması sonucunda belirlenen sistem tasarım isterleri ve sistemin sahip olması gereken fonksiyonlar sırasıyla Tablo 1 ve Tablo 2' de gösterilmiştir. 
Tablo 1. Tasartm İsterleri

\begin{tabular}{|c|c|}
\hline İster & Değer \\
\hline Maksimum Ağırlık & $20 \mathrm{~kg}$ \\
\hline Minimum ayıklama kapasitesi & 25 adet/dakika \\
\hline Bağlantı elemanı maksimum uzunluğu & $100 \mathrm{~mm}$ \\
\hline Giriș gerilimi & $220 \mathrm{~V}$ \\
\hline Sinıflandırma minimum doğruluk oranı & $\% 90$ \\
\hline
\end{tabular}

Tablo 2. Fonksiyonel Isterler

\begin{tabular}{|c|c|c|}
\hline Fonksiyon & İster & İster Karşılama \\
\hline Fonksiyon 1 & Bağlantı elemanlarının sıraya sokulması & Titreşim besleyici \\
\hline Fonksiyon 2 & Bağlantı elemanlarının sıralı biçimde taşınması & Konveyör bant \\
\hline Fonksiyon 3 & Bağlantı elemanlarının sınıflandırılması & Kamera ve görüntü işleme \\
\hline Fonksiyon 4 & Sinıflandırılan elemanların paketlenmesi & Paketleme mekanizmas \\
\hline Fonksiyon 5 & Sistem verilerinin kaydedilmesi ve izlenebilmesi & Kullanıcı arayüzü \\
\hline
\end{tabular}

\subsection{Sistem Mimarisi}

Sistem tasarım isterleri ve fonksiyonel isterler dikkate alınarak genel sistem mimarisi Şekil 1' de gösterildiği gibi belirlenmiştir. Sistem mimarisi titreşimli besleyici, konveyör bant, görüntü işleme birimi ve paketleme mekanizması olmak üzere dört ana birimden oluşacak şekilde belirlenmiştir.

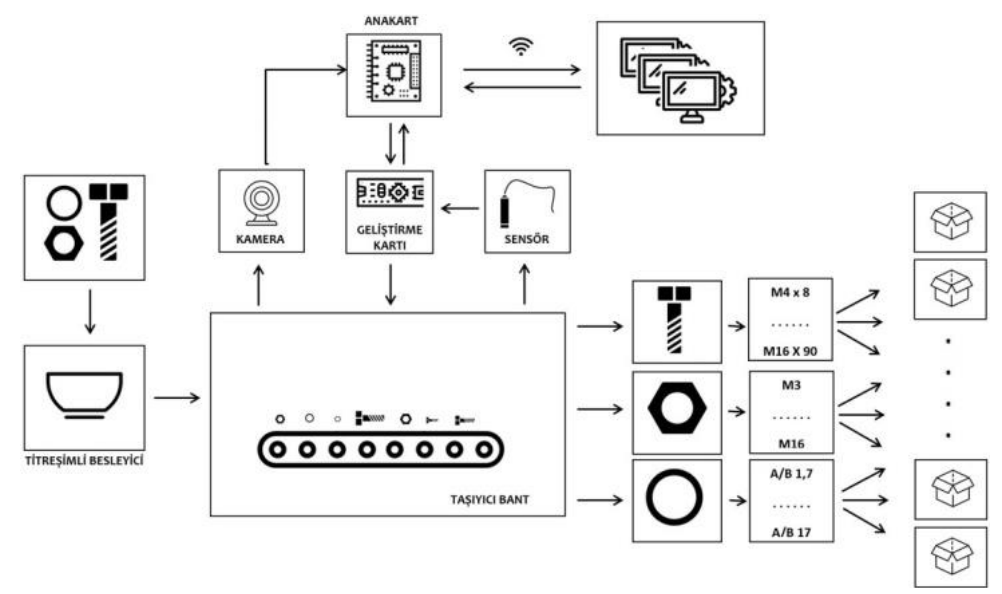

Şekil 1. Sistem blok diyagramı

Sisteme karışık şekilde verilen bağlantı elemanları titreşimli besleyici yardımıyla sıraya sokulur. Bu bağlantı elemanları konveyör mekanizması sayesinde görüntü işleme alanına taşınır. Kamera ve görüntü işleme kartı sayesinde görüntü işleme yöntemi kullanılarak tanımlama işlemi yapılır. Tanımlanan bağlantı elemanları geliştirme kartı aracılığı ile konveyör bant transfer noktasına taşınır. Bu taşıma işlemi esnasında görüntü işleme kartı sayesinde sistem bilgileri senkronize bir şekilde kablosuz ağ aracıllğı ile kullanıcı arayüzüne aktarılmaktadır. Aynı zamanda bu veriler seri haberleşme protokolü kullanılarak kontrol kartı ile iletişim halindedir. Sensörlerden ve görüntü işleme kartından gelen veriler kontrol kartında çalışan kontrol algoritması tarafından yorumlanır. Aynı zamanda, kontrol kartı ile paketleme mekanizması da kontrol edilerek, bağlantı elemanlarının arayüzde tanımlanmış olan kutuya ulaştırılması sağlanmaktadır ve sistemin akışı tamamlanmaktadır.

\subsection{Mekanik Tasarım}

\subsubsection{Titreşim Besleyici}

Görüntü işleme ve sınıflandırma performansının artıırılması adına bir arada bulunan bağlantı elemanlarının ardışık bir sırayla konveyör banda aktarılması önem arz etmektedir. Bunun için dairesel ve doğrusal olmak üzere titreşim besleyici, diğer adı ile vibrasyon besleyici makineleri üretilmiş̧ir [21,22]. Vibrasyon makinesi işlem görecek parçaların dağınık halde bulundukları yerden istenen bölgeye sıralı bir şekilde aktarılma işlemini yapan makinelerdir. Bu çalışma kapsamında dairesel yapıdaki vibrasyon makinesi tercih edilmiş ve gerçekleştirilen tasarım Şekil 2' de gösterilmiştir. Tasarlanan bu titreşimli besleyici ile karışık şekilde atılmış olan bağlantı elemanları ardışık sıra ile konveyör bant sistemine aktarılacaktır. 


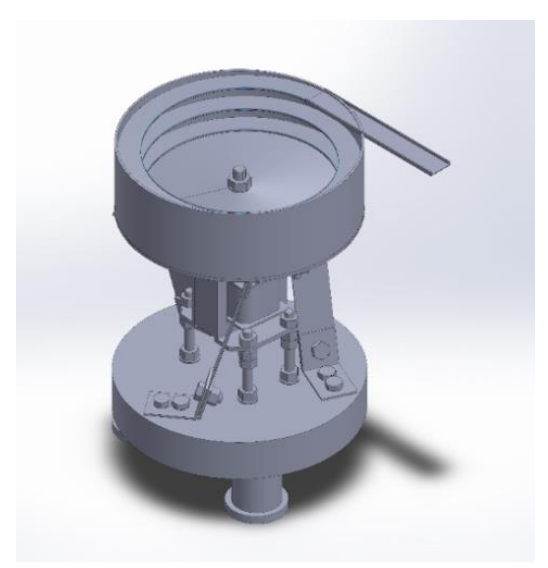

Şekil 2 Titreşim besleyici tasarımı

\subsubsection{Konveyör Bant}

Konveyör bant sistemleri endüstride genellikle ürün ya da malzemelerin farklı işlem süreçleri boyunca iletimi için kullanılmaktadır [23]. Bantlı konveyörlerde malzeme taşınması, germe tamburu ve motor-redüktör sistemi ile hareket verilen tahrik tamburu arasına gerilen bant ile sağlanır. Konveyör bantlar uzunluklarına göre bir, iki ya da daha fazla yerden tahrik edilebilirler. Bu çalışmada sistemin boyutları ve taşınacak parçaların ağırlıkları göz önünde bulundurularak Şekil 3' te gösterilen tek noktadan tahrikli bir konveyör bant sistemi tasarımı gerçekleştirilmiştir.

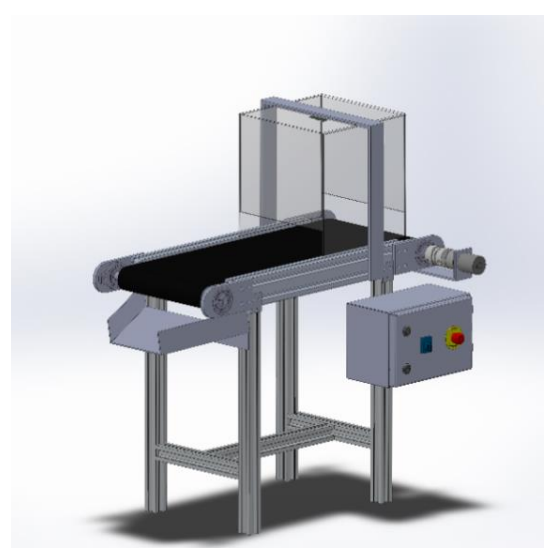

Şekil 3. Konveyor bant sistemi tasarımı

En büyük bağlantı elemanının lineer hızı motorun devir sayısına indirgenerek konveyör motoru için hız değeri 105 dev/dk olarak belirlenmiş̧tir. Bu hız değerine ve $0.74 \mathrm{~kg}$ toplam kütle göz önüne alınarak motorun güç değeri $370 \mathrm{~W}$ ve tork değeri $0.033 \mathrm{Nm}$ olarak hesaplanmıştır. Konveyör motoru için gerekli hesaplamalar yapıldıktan sonra ihtiyaç duyulan tork ve hız değerine uygun motor seçimi yapılmıştır. Seçilen motorun çalı̧̧a eğrileri Şekil 4' te gösterilmiştir.
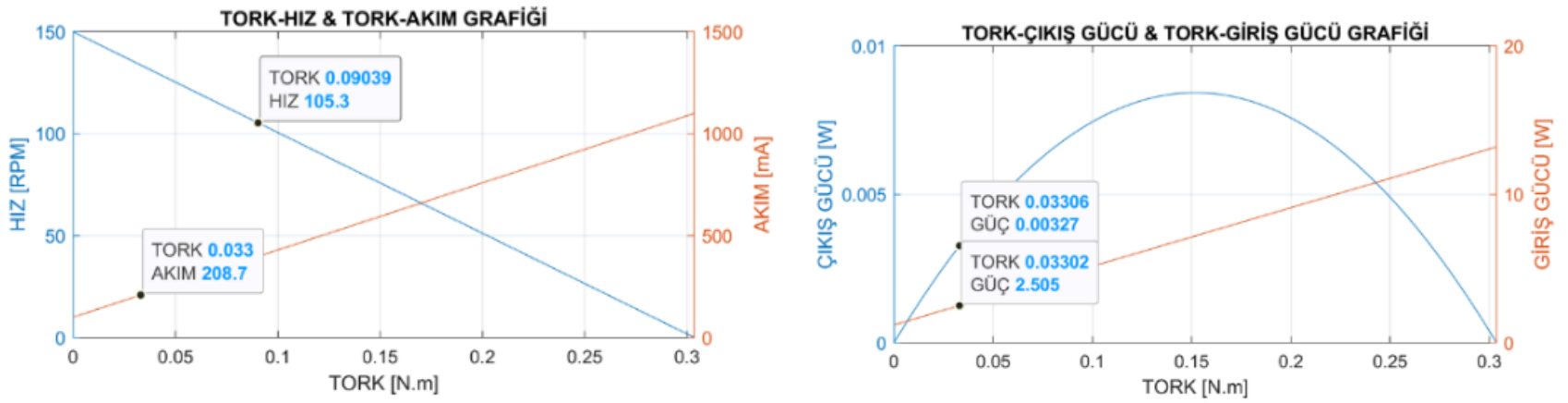

Şekil 4. Konveyör motoru çalışma ĕgrileri

\subsubsection{Paketleme Mekanizmast}

Paketleme mekanizması, sınıflandırılma işlemi tamamlanmış bağlantı elemanlarının uygun paketlere yerleştirilme işlemi için kullanılacak bir mekanizmadır. Bu mekanizma Şekil 5' te gösterildiği gibi toplamda 8 adet kutuyu içerecek şekilde tasarlanmıştır. Bu kutular dönen bir disk üzerine yerleştirilmiştir. Döner disk bir motor ile tahrik edilmektedir. Böylece sınıflandırma işlemi sonucuna göre döner disk açısı kontrol edilerek bağlantı elemanın uygun kutuya bırakılması sağlanmaktadır. 


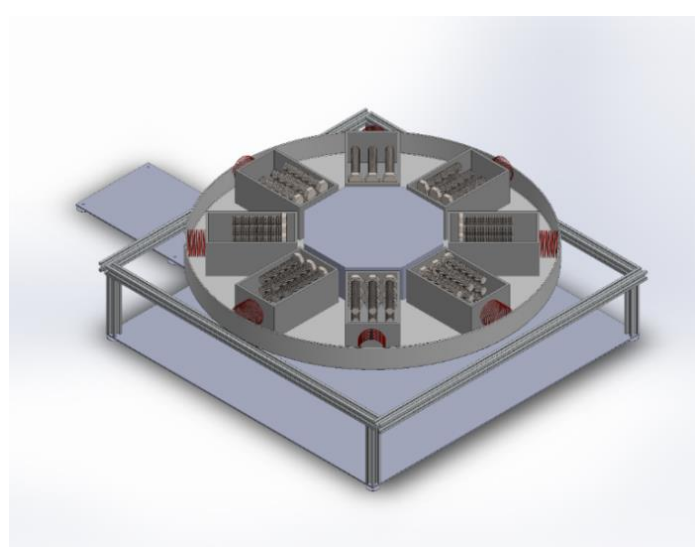

Şekil 5. Paketleme mekanizmast

\subsection{Elektronik Tasarım}

Elektronik tasarım sürecinde sistem isterlerine ve belirlenen sistem mimarisine uygun şekilde alt elektronik komponentlerin seçimi yapılmıştır. Elektronik tasarımı genel bağlantı blok diyagramı Şekil 6' te gösterilmiştir.

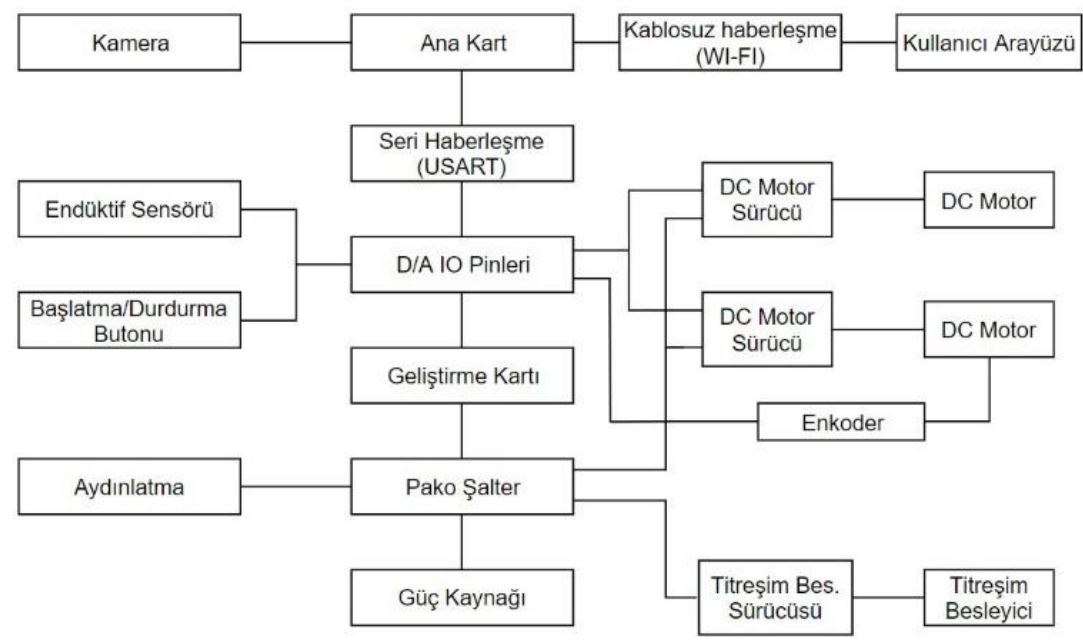

Şekil 6. Elektronik tasarım blok diyagramı

Görüntü İşleme Kartı: Görüntü işleme algoritmasının koşturulacağı işlemci olarak Raspberry PI 4 seçilmiştir. Raspberry PI 4, 64 bit ve $1.5 \mathrm{Ghz}$ ile çalışmaktadır. Aynı zamanda çift-bantlı 2.4/5.0 Ghz'lik Wi-Fi, Bluetooth 5.0 ve USB 2.0/3.0 donanım desteği sunmaktadır. USB 2.0/3.0 donanımı sayesinde USB bağlantısı bulunan çeşitli cihazlar kolaylıkla bağlantı kurabilmektedir.

Kontrol Kartı: Sistem genel kontrol algoritmasının ve alt sistem kontrol algoritmalarının çalıştırılacağı işlemci platformu olarak STM32F407 seçilmiştir. STM32F407 ARM- M4 cortex mimarilidir. $168 \mathrm{MHz}$ çalışma frekans1, 12 bit ADC çözünürlüğü, 82 I/O pin sayıs1, CAN, I2C, SDIO, I2S / SPI, UART / USART, USB gibi haberleşme arayüzleri ve 12 bit DAC çözünürlüğüne sahiptir. Bu üstünlüklerinden dolayı projemizde titreşim besleyici ünitesi, konveyör bant ünitesi ve paketleme ünitesi kontrolünde STM32F4 geliştirme kartı tercih edilmiştir.

Motor Sürücü: Mikrodenetleyicilerin çıkış sinyal seviyeleri DC motorları direkt olarak kontrol etmek için yetersiz olduğundan bu işlem için motor sürücü devreleri kullanılmaktadır. Bu çalışmada ana bant mekanizmasında yer alan DC motor ve paketleme mekanizmasında yer alan enkoder geri beslemeli DC motorun kontrolünde BTS7960B motor sürücüleri kullanılmıştır. Kullanım kolaylığı, kolay temin ve uygun maliyet gibi avantajlarından dolayı bu sürücü tercih edilmiştir.

Kamera: Kameranın 150 mm yükseklikten görüş alanı 150x150 mm² boyutundadır. Bu alanda tespit edilip kontur çizilecek en küçük değer bağlantı elemanı cıvata dişleri olduğundan denetlenecek detayın boyutu bir cıvata dişi yani $0,1 \mathrm{~mm}$ ' dir. Görüntü işleme alanında bir cıvata dişinin tespit edilebilmesi için gerekli kamera çözünürlüğü analitik hesaplamalarla 2.25 MP bulunmuştur. Görüntü işlemede kullanılacak kamera çözünürlüğünün cıvata dişlerini sağlıklı bir şekilde algılayabilmesi için minimum 2.25 MP çözünürlüğüne sahip olması gerekmektedir.

Raspberry PI Kamera Modülünde (V2) 8 MP çözünürlüklü kamera üzerinde sabit odaklı bir lens bulunmaktadır. 3280 x 2464 piksel statik resim çözünürlüğü sunan kamera, video çekimlerinde ise maksimum 1080p: 30fps, 720p: 60fps çözünürlüğünü desteklemektedir. Raspberry PI' ye CSI bağlantısı sayesinde yüksek veri hızı kapasitesine sahiptir ve yalnızca piksel verilerini işlemciye taşımaktadır. Üzerinde Sony firması tarafından üretilen yüksek hassasiyetli ve yüksek hızlı video desteği sunan IMX219PQ görüntü algılayııı sensör bulunmaktadır. Ayrıca otomatik beyaz dengesi, pozlama telafisi kontrolü ve ortam 1şığı algılama gibi özellikleri de bulunmaktadır. Tasarımda bu üstünlüklerinden dolayı bağlantı elemanlarını tür ve boyut olarak görüntü işleyerek tanımlamak amacıyla Raspberry Pi Kamera Modülü (V2) kullanılmıştır. 


\subsection{Kontrol Sistemi Tasarımı}

Konveyör Kontrolü: Endüstriyel uygulamlarda kullanılan denetleyiciler sistem üzerinde bulunan sensörlerden aldı̆̆1 verileri işleyerek kontrol edilmesi istenen sistem değişkeni için uygun kontrol sinyalleri üretmektedir. Bu çalışmada, konveyör sabit hızda hareket edecektir. Konveyör hız kontrolünde PID kontrol yöntemi tercih edilmiştir. PID parametreleri deneme yanılma yöntemi ile belirlenmiştir. Konveyör motorunun kontrolünü gerçekleştirecek kontrol algoritması kontrol kartı üzerinde çalıştırılacaktır.

Titreşimli Besleyici Kontrolü: Vibrasyon makineleri, çanak alt kısmında bulunan bobinin enerjilenmesi ile işlemine başlar. Bu bobinler, seri olarak bağlanmış 2 manyetik alan sargısından oluşmaktadır. Temel olarak yay-kütle sistemlerinde titreşim üretmek için kullanılırlar. Bu bobinler, dairesel vibrasyon dizicilerde ve besleme sistemlerinde gerekli olan titreşimi üretirler. Titreşim bobinleri sürücüler vasıtasıyla uygulanan gerilim ile kontrol edilirler. Vibratör sürücüler, titreşimli besleyicilerin ayarlanabilir bir biçimde denetlenmesini sağlar. Bu sistemde, besleyici kontrolü kontrol kartı üzerinden yapılmaktadır.

Paketleme Mekanizması Kontrolü: Paketleme mekanizmasının kontrolü için geri beslemeli bir kontrol sistemi tasarlanmıştır. Sistemde PID kontrolcü kullanılmış ve parametreleri deneme yanılma yöntemi ile belirlenmiştir. Bu kontrol sisteminde kutuların konveyör bandının transfer noktası ile yaptı̆̆ı açı enkoder geri beslemesi ile elde edilmekte ve parçaların hasar görmeden uygun kutuya ulaşması için motora uygulanması gereken kontrol işareti üretilmektedir. Paketleme mekanizmasının genel işleyiş akış diyagramı Şekil 7' da gösterilmiştir.

Genel Sistem Kontrolü: Arayüzden başla komutu verildiğinde veya fiziksel başla butonuna basıldığında kontrol kartı titreşim besleyiciyi ve konveyör mekanizmasını hareket ettiren motor sürücülerine uygun PWM sinyalleri göndererek çalışmayı başlatmaktadır. $\mathrm{Bu}$ şekilde bağlantı elemanı, sabit hızla hareket eden konveyör bant ile görüntü işleme alanına taşınmaktadır. Görüntü işleme alanında görüntü işleme yazılımı ile tespit edilen eleman bilgisi seri haberleşme (USART) protokolü ile kontrol kartına gelmektedir. Gelen bu bilgilere göre kontol kartı paketleme mekanizmasını daha önceden tanımlı olan açıya getirmektedir. Paketleme mekanizmasının hangi açıda duracağı bilgisi DC motor üzerinde bulunan enkoder ile alınmaktadır. Paketleme mekanizmasında bulunan eleman sayısı bilgileri endüktif sensör yardımıyla sayılarak seri haberleşme ile görüntü işleme kartına oradan da kablosuz ağ vasıtasıyla arayüze aktarımı sağlanmaktadır. Sistemin genel çalışma akış diyagramı Şekil 8' de gösterilmiştir.

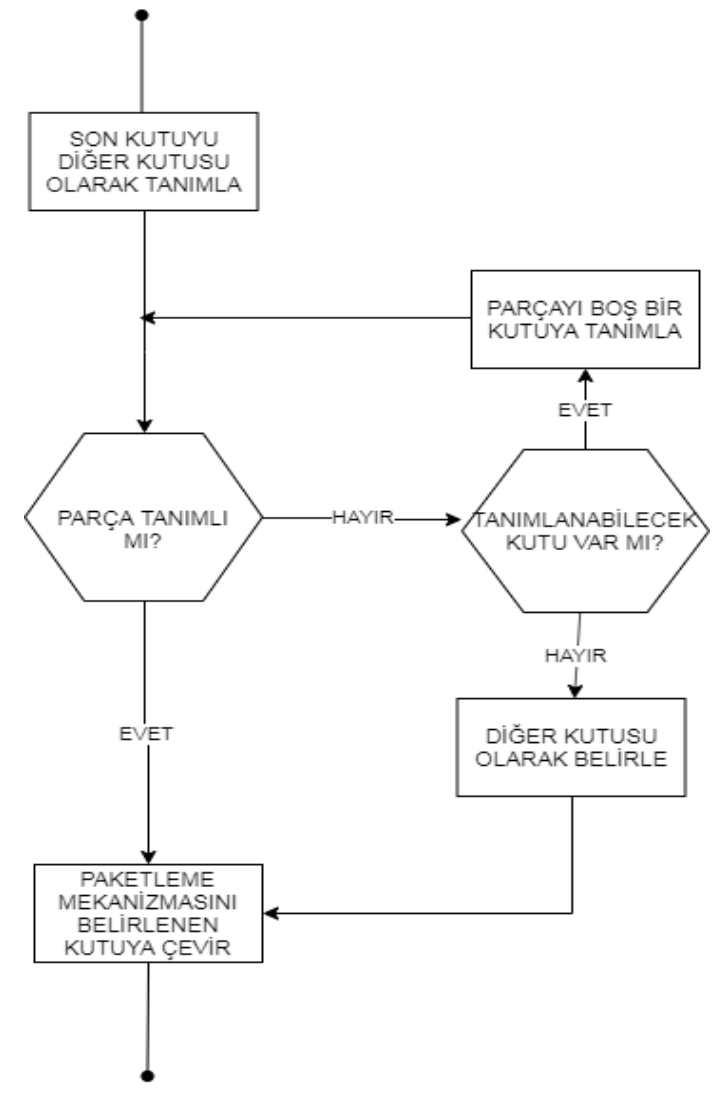

Şekil 7. Paketleme mekanizmasının genel işleyiş akış diyagramı

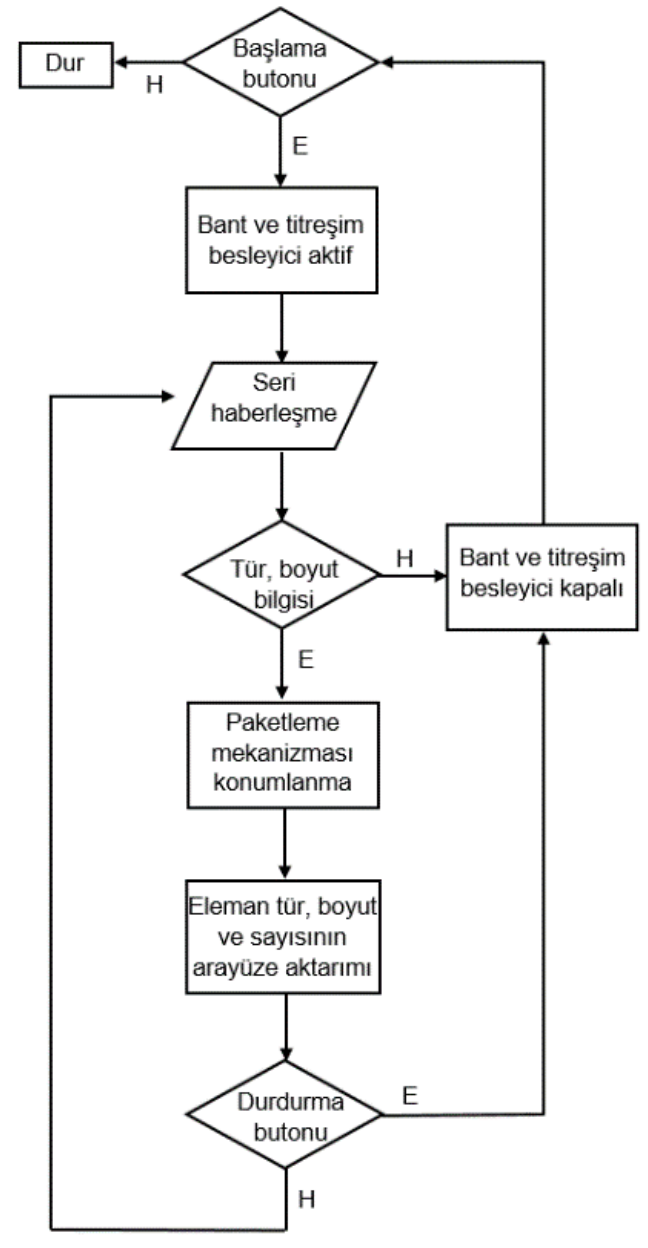

Şekil 8. Sistemin genel çalışma akış diyagramı 


\subsection{Yazılım Geliştirme}

\subsubsection{Genel Yazılım Mimarisi}

Şekil 9' da sistemin genel yazılım mimarisi görülmektedir. Yazılım mimarisi dört katmandan oluşmaktadır. Birinci ve ikinci katmanlar kullanıcı katmanı ve kontrol katmanıdır. Bu katmanlarda kullanıcı arayüzden sisteme müdahale edebilmekte veya sistem hakkında hem görsel hem de yazılı olarak bilgi sahibi olabilmektedir. Üçüncü ve dördüncü katmanlar ise soyutlama ve donanım katmanlarından oluşmaktadır. Bu katmanlar yazılan yazılımlar ve kullanılan elektronik aksamlardan oluşmaktadır. Çalışma kapsamında geliştirilen yazılımlar aşağıda başlıklar halinde açıklanmıştır.

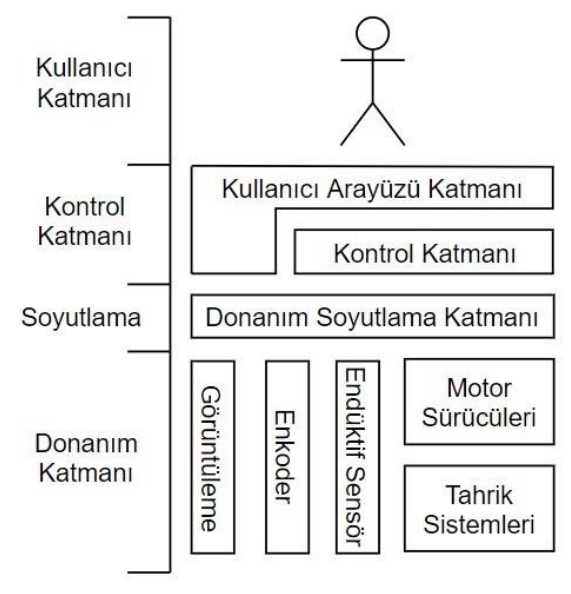

Şekil 9. Yazılım mimarisi

\subsubsection{Görüntü İșleme Yazılımı}

Bir videodaki veya görüntüdeki nesnenin tespiti için iki temel bilgi kullanılır. Bunlar görsel öznitelik (renk, doku, şekil) ve hareket bilgileridir. Bu bilgilerin edinilmesi veya kullanılması için belli bir işlem gücü ve işlem zamanı harcanmaktadır. Nesne tespiti için kullanılan bilgilerin çeşitliliği başarıyı arttırmakla beraber işlem zamanında bir artışa sebep olmaktadır. Bu durum gerçek zamanlı uygulamalarda nesne takibi için oldukça önemli bir problem oluşturmaktadır. Bu çalışmada bağlantı elemanlarını tür ve boyut olarak tanımlamak için Arka Görüntü Modül Çıkartma, Öklid Mesafe Haritası (Euclidian Distance Map) [24] ve Morfolojik (Dilation, Erosion) [25] işlemler uygulanmaktadır.

Görüntü işleme alanına gelen bağlantı elemanının ilk olarak kameradan üç kanallı RGB (Red, Gren, Blue) görüntüsü alınmaktadır. Kameradan alınan görüntü üzerinde sırasıyla bulanıklaştırma (GaussianBlur) [26], resmi grileştirme ve ikili görüntüye çevirme işlemleri (threshold) uygulanmaktadır [27]. Bu işlemlerin gerçekleştirilmesinden sonra ilgilenilen nesne daha belirgin ve kolay işlenebilir bir hale getirilmiş olmaktadır. İkili görüntüye çevirme (threshold) işlemi sonrasında nesne kenarlarını tespit (Canny edge detector) işlemi uygulanmaktadır. Bu işlem sonrasında görüntü üzerinde gürültüler veya istenmeyen alanlar kalabilmektedir. Bu gürültüleri temizlemek amacıyla morfolojik (Dilation, Erosion) [28] işlemler uygulanmaktadır. Öncelikle görüntü üzerine Genişletme (Dilation) sonrasında ise aşındırma (Erosion) işlemi uygulanmaktadır.

Genişletme (Dilation) ikili değerdeki resimlerdeki bir nesneyi alan olarak büyütmek ya da kalınlaştırmak için uygulanan işlemdir. $\mathrm{Bu}$ işlem aynı zamanda aynı nesnenin bir gürültü ile ince bir şekilde bölünerek ayrı iki nesne gibi görünmesini engellemek için kullanılmaktadır. Aşındırma (Erosion) ikili değerdeki resimlerdeki bir nesneyi alan olarak küçültmek ya da inceltmek için uygulanan işlemdir. Bu işlem aynı zamanda birbirine ince bir gürültü ile bağlanmış iki veya daha fazla nesneyi birbirinden ayırmak için kullanılmaktadır.

$\mathrm{Bu}$ işlemlerin sonrasında ikili değerdeki görüntü üzerinde kontur çizdirilmekte ve önceden yapılmış olan testler ile bağlantı elemanlarına karşılık gelen kontur sayıları bilinmektedir. Bu kontur sayısına göre bağlantı elemanının türü civata, somun veya pul olarak tespit edilmektedir. Ayrıca Öklid Mesafe Haritası (Euclidian Distance Map) işlemi ile bağlantı elemanlarının metrik bilgisi tespit edilmektedir. Bu tanımlama işlemleri sonrasında görüntü işleme kartı seri haberleşme protokolü ile kontrol kartına ve aynı zamanda kablosuz ağ teknolojisi ile C\# ortamında tasarlanmış olan cihaz arayüzüne tanımlanan bilgiyi göndermektedir. Şekil 10' da görüntü işlemede yapılan işlemlerin sırası bir M10 cıvata örnek alınarak gösterilmiştir. Somun ve pul elemanlarının tanımlanmasında da aynı işlemler kullanılmaktadır. 


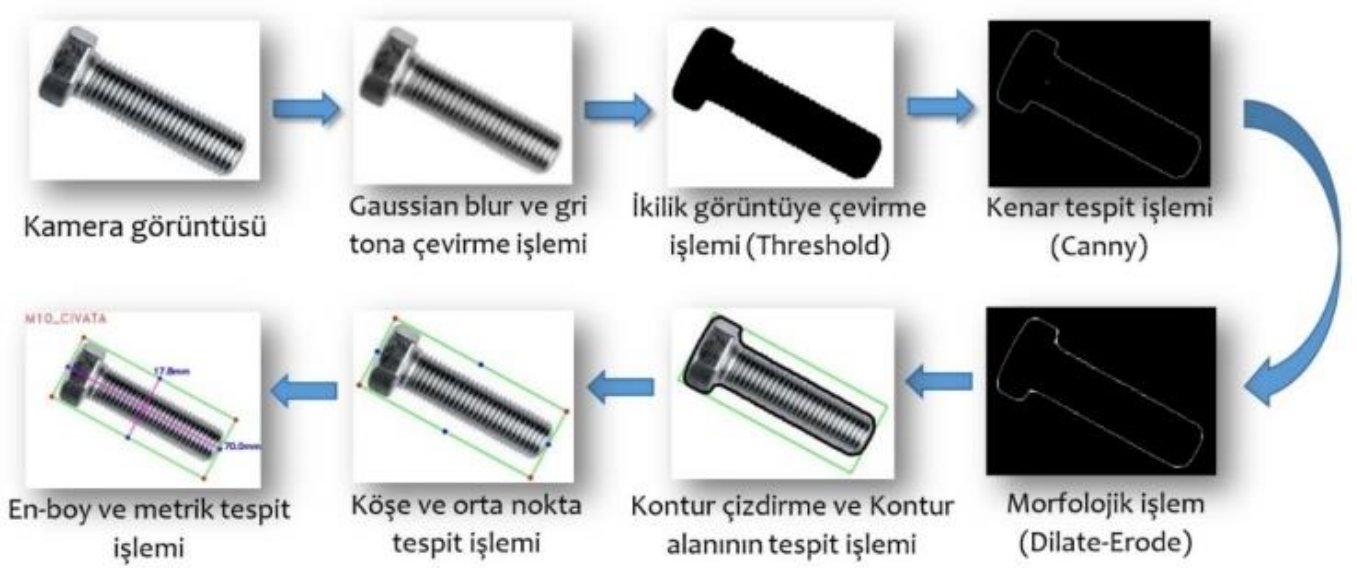

Şekil 10. Örnek bir clvata üzerinden görüntü işleme adımlarının gösterimi

\subsubsection{Kullanıcı Arayüzü Yazılımı}

Geliştirilen arayüz ekranında, sistemdeki parçaların arıza durumları, kutuların içerik bilgisi, bant hızı, motorların akım ve gerilim değerleri gibi bilgiler gösterilmektedir. Sistemin çalıștıılması ve durdurulması sistem üzerindeki fiziksel buton yardımı ile kontrol edilebildiği gibi arayüz üzerinden de kontrol edilebilmektedir. Bunların yanı sıra, sistem çıktıları kontrol amaçlı olarak kayıt altında tutulmakta ve kullanıcıya grafiksel olarak gösterilmektedir.

Kutuların içerik bilgileri ve doluluk oranlarının gösterildiği grafiksel kullanıcı arayüzü monitör ekranı Şekil 11a' da gösterilmiştir. Şekil 11b' de gösterilen ayarlar ekranında ise kutulara tanımlama işlemi yapılabilmektedir. Bu tanımlama yapılmadığında kutu tanımlamaları görüntü işleme sonrası sınıflandırılan bağlantı elemanının türüne göre otomatik olarak gerçekleştirilmektedir. Açık, kapalı ve acil durdurma butonları ile sistemin çalışma durumları kontrol edilmektedir. Sistem ayarları butonu ile açlacak ve Şekil $11 \mathrm{c}^{\prime}$ de gösterilen sayfada bağlantı yapılacak IP adresi ve kaç saniyede bir veri alınması gibi ayarlar yapılmaktadır. Yazılımının kontrol edilmesi için FTP aracılı̆̆ ile verilerin alınması işlemi gerçekleştirilmiştir.

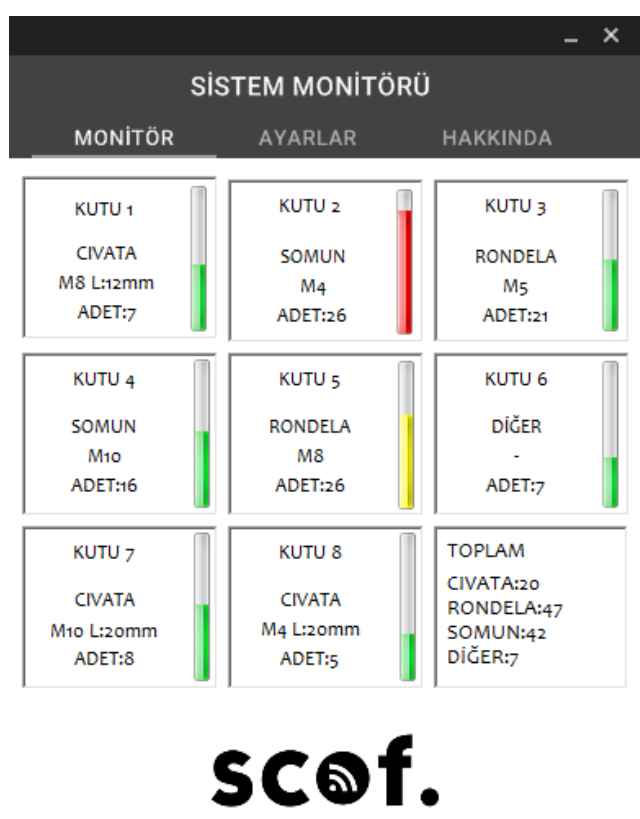

a)

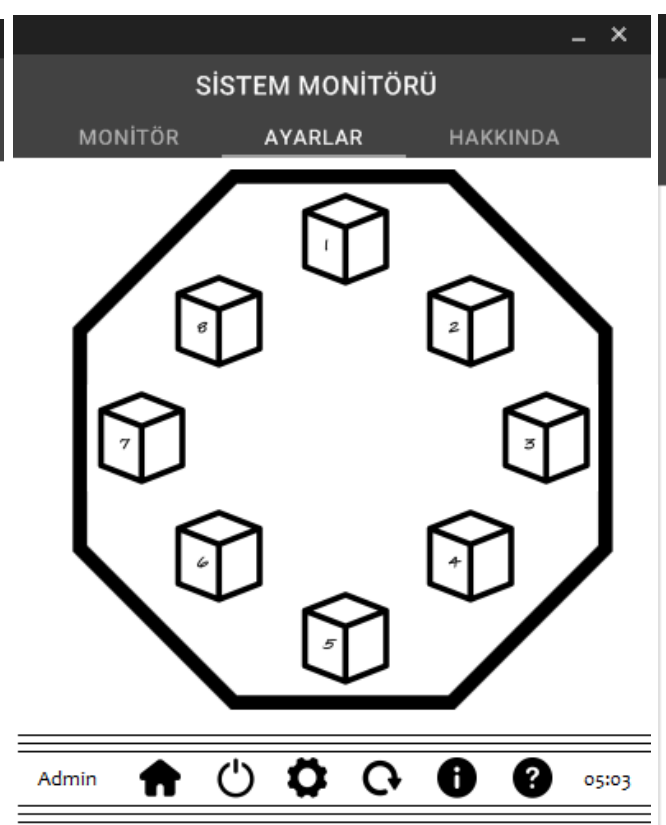

b)

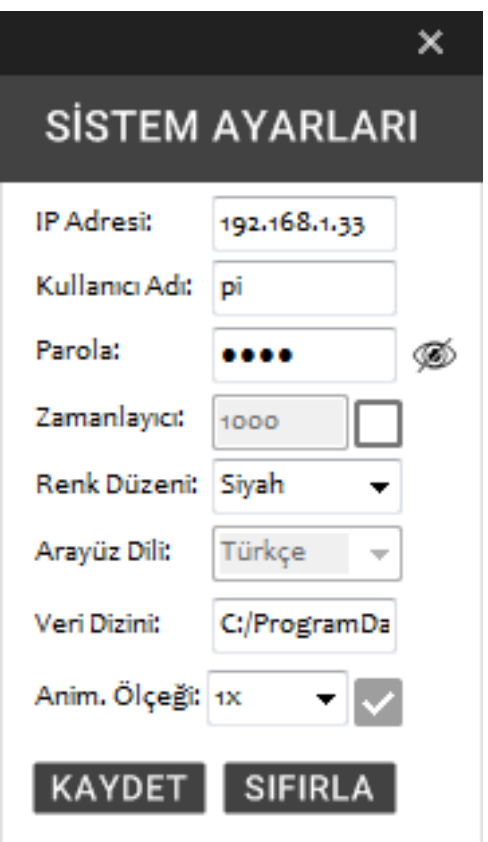

c)

Şekil 11. Kullanıcı arayüzü a) monitör ekranı b) ayarlar ekranı c) sistem ayarları

\subsubsection{Kontrol Yazılımı}

Kontrol kartınında çalışan ana kontrol algoritmasının görevi temel olarak görüntü işleme kartı üzerinden aldığı bilgilere göre konveyör ve paketleme mekanizmasını kontrol etmektir. Tanımlanan bağlantı elemanı bilgileri seri haberleşme protokolü USART ile geliştirme kartına 4 baytlık paketler halinde gelmektedir. Her bir paket içeriğinde durum, eleman tür bilgisi, metrik ve eleman uzunluğu baytları yer almaktadır. Tasarlanan konveyör ve paketleme mekanizması kontrol algoritmaları koda çevrilerek ilgili gömülü kontrol yazılımı gerçekleştirilmiştir. 


\section{Sistem Entegrasyonu ve Testler}

Sistemin nihai tasarımı Şekil 12 'te gösterilmiştir. Bu tasarıma uygun şekilde sistem parçaları tornalama, matkap, taşlama yöntemleri kullanılarak üretilmiş ve sistem entegrasyonu yapılarak sistem fonksiyonel testler için hazır hale getirilmiştir. Entegrasyonu tamamlanmış sistem Şekil 13'de ve Şekil 14'de gösterilmiştir. Sistemin temel fonksiyonel testleri başarıyla gerçekleştirilmiş ve konveyör bant, paketleme mekanizması ve titreşim mekanizmasının istenen tasarım kriterlerini karşıladığı görülmüş̧ür.

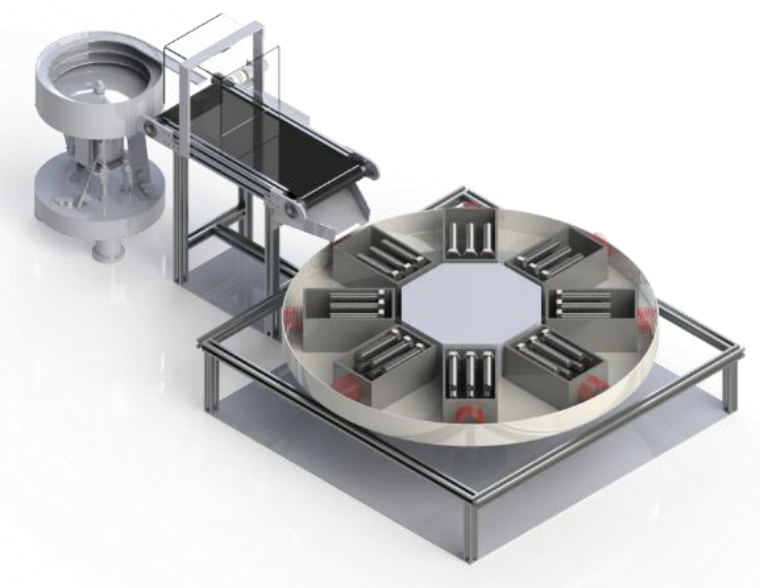

Şekil 12. Tüm sistem tasarımı

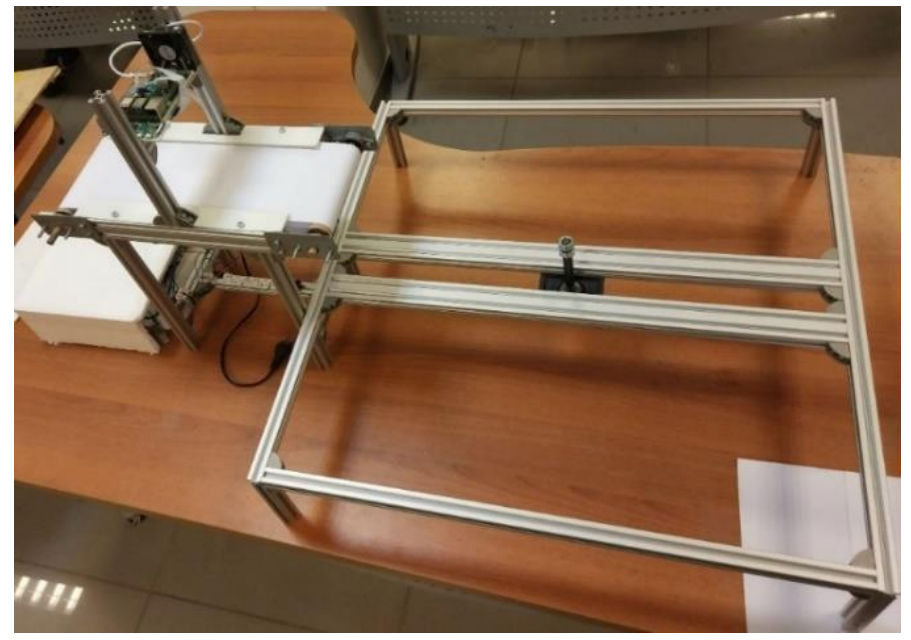

Şekil 13. Tamamlanmış sistem tasarımı (1)

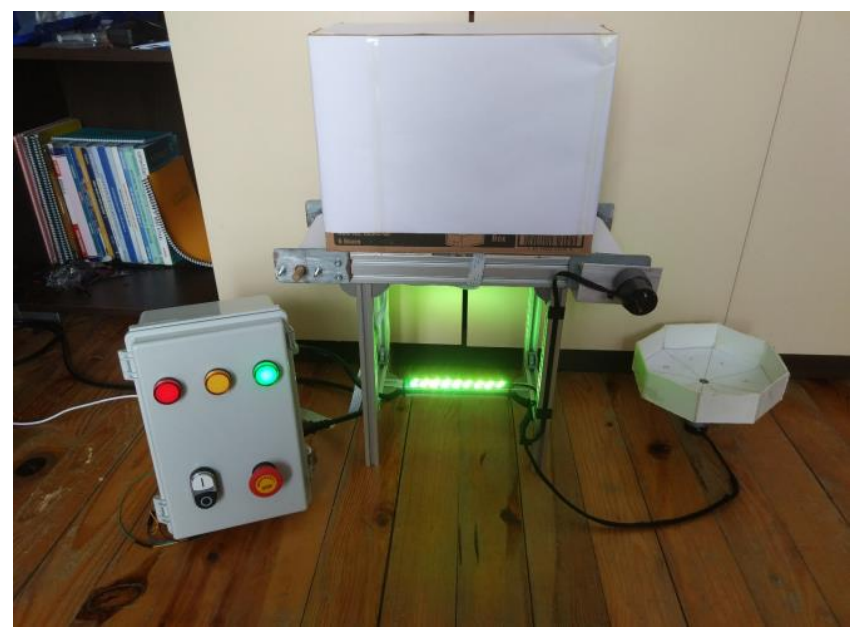

Şekil 14. Tamamlanmış sistem tasarımı (2) 
Görüntü işleme ile gerçekleştirilen sınıflandırma performansını değerlendirmek için farklı özelliklere sahip 21 adet bağlantı elemanı onar kez farklı açı ve konumlarda görüntü işleme biriminden geçirilmiş ve böylece 210 adet durum için görüntü işleme fonksiyonel testi gerçekleştirilmiş̧ir. Bu testin sonunda 200 adet doğru sınıflandırma gerçekleştirilmiştir. Test sonuçları Tablo 3 'de verilmiştir.

Tablo 3. Görüntü İsleme Test Verileri

\begin{tabular}{|c|c|c|c|}
\hline Test & Test Örnek Sayısı & Doğru Tespit Sayısı & Başarım Oranı \\
\hline Tür Tespiti & 210 & 200 & $\% 95.24$ \\
\hline Metrik Tespiti & 180 & 166 & $\% 92.22$ \\
\hline Uzunluk Tespiti & 80 & 78 & $\% 97.50$ \\
\hline Tür, Metrik ve Uzunluk Olarak Genel Tespit & 190 & 172 & $\% 90,52$ \\
\hline
\end{tabular}

Tablo 3'den görüldüğü gibi bağlantı elemanlarının tür bilgisinin tespitinde elemanı doğru bir şekilde tanımlama oranı \%95.24 olarak hesaplanmıştır. Metrik tespiti yapılabilecek 180 eleman arasından algoritma 166 adet doğru tespit gerçekleștirmiş̧ir. Elemanın metrik bilgisinin tespitinde elemanı doğru bir şekilde tanımlama oranı \%92.22 olarak hesaplanmıştır. Uzunluk tespiti yapılabilecek 80 eleman arasından algoritma 78 adet görüntüyü doğru olarak tespit etmiştir. Elemanın uzunluk bilgisinin tespitinde elemanı doğru bir şekilde tanımlama yüzdeliği \%97.50 olarak hesaplanmıştı. Son olarak elemanın tür, metrik ve uzunluk bilgisi olarak genel çerçeveden bakıldığında elemanın doğru tespit edilme yüzdeliği \%90.52 şeklindedir. Böylece gerçekleștirilen görüntü işleme fonksiyonel testleri ile istenen sınıflandırma doğruluk oranın sağlandığı gösterilmiştir. Testlere ait örnek görüntüler Şekil 15' te gösterilmiştir.
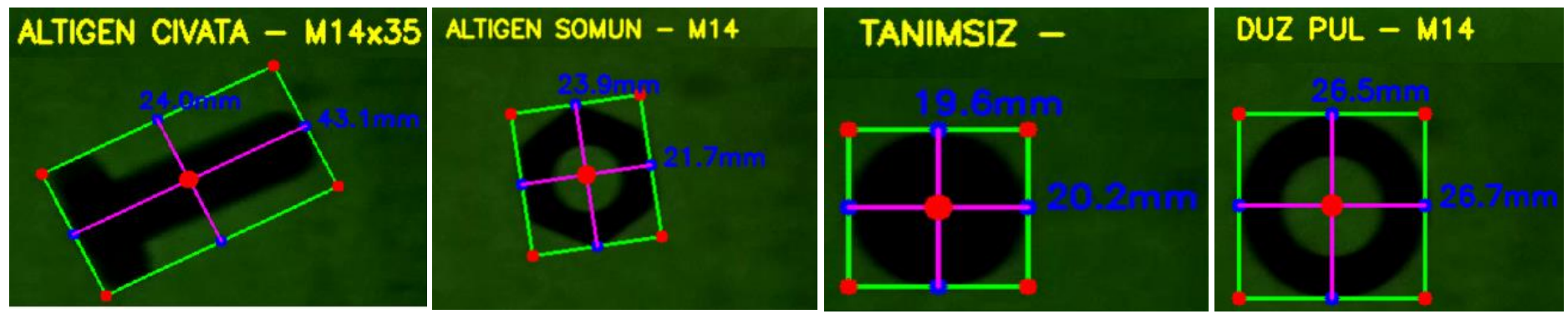

Şekil 15. Görüntü işleme birimi fonksiyonel testlerinden örnek görüntüler

\section{Sonuçlar}

Bu çalışmada makine bağlantı elemanlarını ayıklama sistemi geliştirilmesi gösterilmiştir. Öncelikle belirlenen tasarım isterleri ve fonksiyonel isterlere bağlı olarak sistem mimarisi tasarlanmıştır. Sistem mimarisinde belirlenen alt sistemlerin mekanik ve elektriksel tasarımları gerçekleştirilmiştir. Ardından ilgili kontrol, görüntü işleme, haberleşme ve kullanıcı arayüzü yazılımları geliştirilmiştir. Sonrasında tasarlanan alt sistemlerin üretimi gerçekleştirilmiş ve sistem entegrasyonun ardından fonksiyonel testler gerçekleştirilmiştir. Elde edilen test sonuçları ile geliştirilen sistemin tasarım kriterlerini sağladığı gösterilmiştir. Özellikle elde edilen \%90 değerinin üzerinde bir sınıflandırma doğruluk oranı ile sistemin etkin bir şekilde bağlantı elemanı ayılma işlemlerinde kullanılabileceği doğrulanmıştır.

Endüstride ve atölyelerde insan gücüyle yapılan, iş gücü ve zaman kaybına neden olan bu bağlantı elemanı ayıklama işlemi geliştirilen sistem ile otomatik bir şekilde daha hatasız ve verimli bir sürede etkili biçimde yapılabilecektir.

\section{Teşekkür}

Bu çalışma TÜBİTAK (Proje No: 1139B411901085) tarafından desteklenmiştir. Ayrıca TT\&Sigma A.Ş’ya desteklerinden dolayı teşekkürlerimizi sunarız.

\section{Kaynakça}

[1] Ekici, Süleyman \& Erbil, Emre \& Bıyık, Aysel. (2016). Bağlantı Elemanı Ayıklama Uygulamalarında Makine Vizyonu Teknikleri. 9. 82-92.

[2] Daniyan, I. A., Adeodu, A. O. and Dada, O. M. (2014). Design of a Material Handling Equipment: Belt Conveyor System for Crushed Limestone Using 3 Roll Idler. Journal of Advancement in Engineering and Technology. pp. 1-7.

[3] Standard for Conveyor Belt Covers, H. Simonsen Consultant, Sept. 1990 Manager R \& D, Germany, Sept. 1990.

[4] Besser Service Bulletin. (2006). Conveyor Belt Basic Rules and Procedure for Tracking. pp. 1-7

[5] García-Martín, Javier \& Gomez-Gil, Jaime \& Vázquez-Sánchez, Ernesto. (2011). Non-Destructive Techniques Based on Eddy Current Testing. Sensors (Basel, Switzerland). 11. 2525-65. 10.3390/s110302525. 
[6] Feng, Hao \& Jiang, Zhiguo \& Xie, Fengying \& Yang, Ping \& Shi, Jun \& Chen, Long. (2014). Automatic Fastener Classification and Defect Detection in Vision-Based Railway Inspection Systems. Instrumentation and Measurement, IEEE Transactions on. 63. 877-888. 10.1109/TIM.2013.2283741.

[7] D'Angelo, Gianni \& Rampone, Salvatore. (2015). Shape-based defect classification for Non Destructive Testing. 2nd IEEE International Workshop on Metrology for Aerospace, MetroAeroSpace 2015 - Proceedings. $406-410$. 10.1109/MetroAeroSpace.2015.7180691.

[8] Xiukun Wei, Ziming Yang, Yuxin Liu, Dehua Wei, Limin Jia, Yujie Li, Railway track fastener defect detection based on image processing and deep learning techniques: A comparative study, Engineering Applications of Artificial Intelligence, Volume 80, 2019, Pages 66-81, ISSN 0952-1976.

[9] P. Viola and M. Jones, "Rapid object detection using a boosted cascade of simple features," Computer Vision and Pattern Recognition, 2001. CVPR 2001. Proceedings of the 2001 IEEE Computer Society Conference on, vol: 1, pp.:I-511-I518, 2001.

[10]R. Hussin, M.R. Juhari, N.W. Kang, R.C. Ismail and A. Kamarudin, "Digital image processing techniques for object detection from complex background image". Procedia Engineering, vol:41, pp:340-344, 2012

[11]M. Sonka, V. Hlavac and R. Boyle, "Image processing, analysis, and machine vision. Cengage Learning", 2014

[12]Attica Automation Inc., AVB100, Erişim adresi: http://www.atticaautomation.com/wpcontent/uploads/2019/06/Attica_Booklet.pdf

[13]Delta Vision, DV-RDSM - Rotary Disc Sorting Machine, Erişim adresi: http://www.deltavisione.com/files/33826_Delta_Visione_Brochure_Selezionatrici_ENG_02_2018.pdf

[14]S, Shilpashree \& Hlmg, Lokesha \& Shivkumar, Hadimani. (2015). Implementation of Image Processing on Raspberry Pi. IJARCCE. 4. 199-202. 10.17148/IJARCCE.2015.4545.

[15]Bordignon, Lucas \& Von Wangenheim, Aldo. (2019). Benchmarking Deep Learning Models on Jetson TX2. 10.13140/RG.2.2.28466.15040.

[16]P. Viola and M. Jones, "Rapid object detection using a boosted cascade of simple features," Computer Vision and Pattern Recognition, 2001. CVPR 2001. Proceedings of the 2001 IEEE Computer Society Conference on, vol: 1, pp.:I-511-I518, 2001.

[17]Y. Zhang, et al., "Gilbreth: A Conveyor-Belt Based Pick-and-Sort Industrial Robotics Application," in 2018 Second IEEE International Conference on Robotic Computing (IRC), Laguna Hills, CA, USA, 2018 pp. 17-24.

[18]Silversides, Richard \& Dai, Jian \& Seneviratne, Lakmal. (2005). Force Analysis of a Vibratory Bowl Feeder for Automatic Assembly. Journal of Mechanical Design - J MECH DESIGN. 127. 10.1115/1.1897407.

[19]Ramalingam, M., \& Samuel, G. L. (2008). Investigation on the conveying velocity of a linear vibratory feeder while handling bulksized small parts. The International Journal of Advanced Manufacturing Technology, 44(3-4), 372-382.

[20]Abdulla, Shaeez \& K., Kunhimohammed \& K., Muhammed \& S., Sahna \& S., Gokul. (2016). Automatic Color Sorting Machine Using TCS230 Color Sensor And PIC Microcontroller. International Journal of Research and Innovations in Science and Technology, ISSN 2395-3858, Jan, 2016. 2.

[21]Gladwell G. M. L., and Masour W. M., 1971, "Simulation of Vibratory Feeders, Proc. Of the Symp. on Computer-Aided Engineering," Univ. Waterloo, pp. 215-249.

[22]Mansour W. M., 1972, “Analog and Digital Analysis and Synthesis of Oscillatory Tracks,” ASME J. Eng. Ind., 94(2), pp. 488-494.

[23]M.A, A., Latest Developments in Belt Conveyor Technology. MINExpo 2004, Las Vegas, NV, USA. September 27, (2004). 2004.

[24]S. Bellal, H. Mouss and R. Bensaadi, "Recognition of objetcts in an image for triage," 2013 International Conference on Control, Decision and Information Technologies (CoDIT), Hammamet, 2013, pp. 359-365.

[25]Xu, Dong \& Li, Hua. (2006). Euclidean Distance Transform of Digital Images in Arbitrary Dimensions. 4261. $72-79$. 10.1007/11922162_9.

[26]Srisha, Ravi \& Khan, Am. (2013). Morphological Operations for Image Processing : Understanding and its Applications.

[27]Gedraite, Estevao \& Hadad, M.. (2011). Investigation on the effect of a Gaussian Blur in image filtering and segmentation. 393396.

[28]Ismail, Abdul Halim \& Marhaban, Mohammad Hamiruce. (2009). A simple approach to determine the best threshold value for automatic image thresholding. 10.1109/ICSIPA.2009.5478623. 